\title{
Transition Metal Complex Cations as Reagents for Gas-Phase Transformation of Multiply Deprotonated Polypeptides
}

\author{
David M. Crizer, Yu Xia, and Scott A. McLuckey \\ Department of Chemistry, Purdue University, West Lafayette, Indiana, USA
}

Triply deprotonated DGAILDGAILD was reacted in the gas-phase with doubly charged copper, cobalt, and iron metal complexes containing either two or three phenanthroline ligands. Reaction products result from two major pathways. The first pathway involves the transfer of an electron from the negatively charged peptide to the transition-metal complex. The other major pathway consists of the displacement of the phenanthroline ligands by the peptide resulting in the incorporation of the transition-metal into the peptide to form $[\mathrm{M}-3 \mathrm{H}+$ $\left.\mathrm{X}^{\mathrm{II}}\right]^{-}$ions, where $\mathrm{X}$ is $\mathrm{Cu}, \mathrm{Co}$, or Fe, respectively. The extent to which each pathway contributes is dependent on the nature of transition-metal complex. In general, bis-phen complexes result in more electron-transfer than the tris-phen complexes, while the tris-phen complexes result in more metal insertion. The metal in the complex plays a large role as well, with the $\mathrm{Cu}$ containing complexes giving rise to more electron transfer than the corresponding complexes of $\mathrm{Co}$ and Fe. The results show that a single reagent solution can be used to achieve two distinct sets of products (i.e., electron-transfer products and metal insertion products). These results constitute the demonstration of novel means for the gas-phase transformation of peptide anions from one ion type to another via ion/ion reactions using reagents formed via electrospray ionization. (J Am Soc Mass Spectrom 2009, 20, 1718-1722) (c) 2009 American Society for Mass Spectrometry

$\mathrm{T}$ landem mass spectrometry (MS/MS) has become a very powerful tool for the structural characterization of biological molecules [1], with peptides constituting a prominent example. Collision induced dissociation (CID), which tends to result in cleavage of amide bonds in peptide cations, giving b- and y-type fragment ions, is by far the most commonly used method for dissociating peptide ions [2]. No single approach, however, provides all the structural information of interest in all scenarios. A drawback of CID, for example, is that it tends to lead to the loss of labile groups, such as post-translational modifications (PTMs), which complicates the assignment of their locations. Alternative methods, such as electron capture dissociation (ECD) [3] and electron-transfer dissociation (ETD) [4], are being used to complement CID. The closely related ECD and ETD methods lead to the cleavage of $\mathrm{N}-\mathrm{C}_{\alpha}$ bonds, giving rise to formation of c- and z-type fragment ions, and tend not to give rise to loss of labile side-chain modifications.

The extent of structural information that can be obtained from a gaseous ion is highly dependent upon the nature of the ion (i.e., protonated molecule, radical

Address reprint requests to Dr. S. A. McLuckey, Department of Chemistry, Purdue University, 1393 Brown Laboratories, West Lafayette, IN 479071393, USA. E-mail: mcluckey@purdue.edu cation, deprotonated molecule, etc.). ETD and ECD are restricted to positive ions and, for practical purposes, the positive reactant ions must be multiply charged. However, many analyte species, including acidic peptides, are more readily formed as anions. The CID of deprotonated peptides, therefore, has been explored [5, 6], as have ion/electron and ion/ion reactions involving negatively charged bio-ions. For example, the phenomenon of electron detachment dissociation (EDD) of peptide anions [7], whereby dissociation occurs as a result of the ejection of an electron under electron bombardment conditions, has been described. EDD of peptides results in the cleavage of $\mathrm{C}_{\alpha}-\mathrm{C}$ bonds, which leads to a- and $x$-type fragments. EDD has also been applied to other bio-anions, such as glycosaminoglycan carbohydrates [8] and oligonucleotides [9]. The ion/ion reaction analog to EDD was first demonstrated in the transfer of an electron from multiply deprotonated oligonucleotides to ionized xenon [10]. Coon et al. have recently used ionized xenon to fragment deprotonated peptides, referring to the overall process as negative electron-transfer dissociation (NETD) [11]. Both EDD and ion/ion electron-transfer from a multiply charged anion yield species of the form $[\mathrm{M}-\mathrm{nH}]^{(\mathrm{n}-1)-\bullet}$, which are generally difficult to generate directly with common ionization methods. However, Lam and Chu recently reported the formation of angiotensin $[\mathrm{M}-2 \mathrm{H}]^{-\bullet}$ from 
the CID of $\left[\mathrm{Mn}^{\mathrm{III}}(\text { salen})(\mathrm{M}-2 \mathrm{H})\right]^{-\bullet}$ species formed from negative electrospray of a solution comprised of a mixture of the peptide, $\mathrm{M}$, with $\mathrm{Mn}^{\mathrm{III}}$ complexed to one of a variety of salen ligand derivatives [12].

While peptides are generally readily formed as either proton deficient species or proton rich species, it is also possible to form gaseous peptides associated with metal cations. An extensive literature now exists that is devoted to the dissociation behavior of polypeptides with one or more excess metal cations [13-15], and these studies often find that structural information complementary to that derived from exclusively protonated species can be obtained. The fragmentation behavior of peptide anions that also contain one or more metal counter-ions is little explored, however. Recently, we described the use of transition-metal complex cations for gas-phase insertion of a transition-metal into oligonucleotide anions and for extracting an electron from oligonucleotide anions [16]. Both types of reactions result in the transformation of multiply deprotonated oligonucleotides into another ion type (i.e., an oligonucleotide anion with a transition-metal counter-ion and a distonic radical anion, respectively). Here we describe gas-phase ion/ion reactions between metal complex cations and multiply deprotonated peptides as means for generating different ion types from peptide anions that are readily formed by electrospray.

\section{Experimental}

\section{Mass Spectrometry}

Nanospray emitters were pulled from borosilicate capillaries (1.55 mm o.d., $0.86 \mathrm{~mm}$ i.d.) using a P-87 Flaming/Brown micropipet puller (Sutter Instruments, Novato, CA, USA). These nanospray tips were loaded with the electrospray solutions, and a metal wire was inserted into the tip to make electrical contact with the solution [17]. For peptide solutions, a stainless steel wire was used, while a platinum wire was used for metal complex solutions.

Ionization was performed using a home-built pulsed dual nanoelectrospray ionization (nano-ESI) source that has been previously described [18]. A quadrupole/ time-of-flight tandem mass spectrometer (QSTAR XL; Applied Biosystems/MDS SCIEX, Concord, ON, Canada) that has been modified for ion/ion reactions was used for all experiments [19]. The instrument was controlled by a research version of Daetalyst (MDS SCIEX), which provided full control for initiating each ion source and for applying the appropriate potentials and their timing to the ion path.

A typical experiment consisted of producing peptide anions via the negative nano-ESI source and isolating the ions of interest as they passed through Q1. The isolated anions were then directed into the Q2 linear ion trap (LIT) (200 ms), where they were trapped. The metal phenanthroline complexes were then generated in the gas phase by positive nano-ESI of the corresponding metal solution, mass-selected by Q1, and introduced into the Q2 LIT (100 ms), where ions of both polarities were allowed to react in the LIT $(50 \mathrm{~ms})$. Ion/ion reaction products were then mass analyzed by a reflectron time-of-flight (TOF) analyzer $(150 \mathrm{~ms})$. The spectra shown here are typically averages of 100 cycles. Data shown were normalized to the most abundant product ion.

\section{Solutions for Nano-ESI}

The peptide DGAILDGAILD was synthesized by SynBioSci (Livermore, CA, USA). Phosphopeptide LPISASHpSpSKTR was synthesized by CPC Scientific (San Jose, CA, USA). Both peptides were diluted to a concentration of $20 \mu \mathrm{M}$ in 49/49/2 (vol/vol/vol) methanol/water/ammonium hydroxide solution. Preparation of the metal complexes involved the mixing of a metal salt and 1,10-phenanthroline (phen) (Sigma-Aldrich, St. Louis, MO, USA) in a methanolic solution to a concentration of $0.1 \mathrm{mg} \mathrm{mL}^{-1}$. Metal salts used for phenanthroline complexes were copper (II) nitrate hemi(pentahydrate), cobalt (II) chloride hexahydrate, and iron (II) sulfate heptahydrate. These metal salts were obtained from Sigma-Aldrich and were used without further purification.

\section{Results and Discussion}

Triply deprotonated DGAILDGAILD was used as a model peptide anion for reaction with the bis- and tris-phenanthroline complexes of $\mathrm{Co}^{\mathrm{II}}, \mathrm{Cu}^{\mathrm{II}}$, and $\mathrm{Fe}^{\mathrm{II}}$. Figure 1 shows the spectra from the reactions between the triply deprotonated peptide and the bis-phenanthroline (Figure 1a-c) and the tris-phenanthroline (Figure 1d-f) complexes. The copper containing bis-phen complex gives rise to extensive electron-transfer products. These products include a- and x-type fragment ions from NETD, yielding complete sequence coverage in this case, as well as intact charge-reduced species. Similarly, reaction of the peptide with the iron and cobalt bis-phen complexes results in both products from electron-transfer and metal insertion, although metal insertion is much more prominent with the complexes of these two metals. Use of the cobalt complex gives rise to slightly more a- and $x$-type ions than does the use of the iron complex. The reactions between the tris-phenanthroline metal complexes and the deprotonated peptide lead predominantly to metal insertion for all three metals.

These results show that the reaction of transition metal-phenanthroline complexes with deprotonated peptides can give products corresponding to two major pathways, electron-transfer and metal insertion. The number of ligands attached to the metal plays a major role in determining which pathway is more favorable. The bis-phen complexes result in significant amounts of both electron-transfer and metal insertion, while the tris-phen complexes result in almost entirely metal insertion. The summary of the percentages of observed products from each pathway is shown in Table 1 . The 


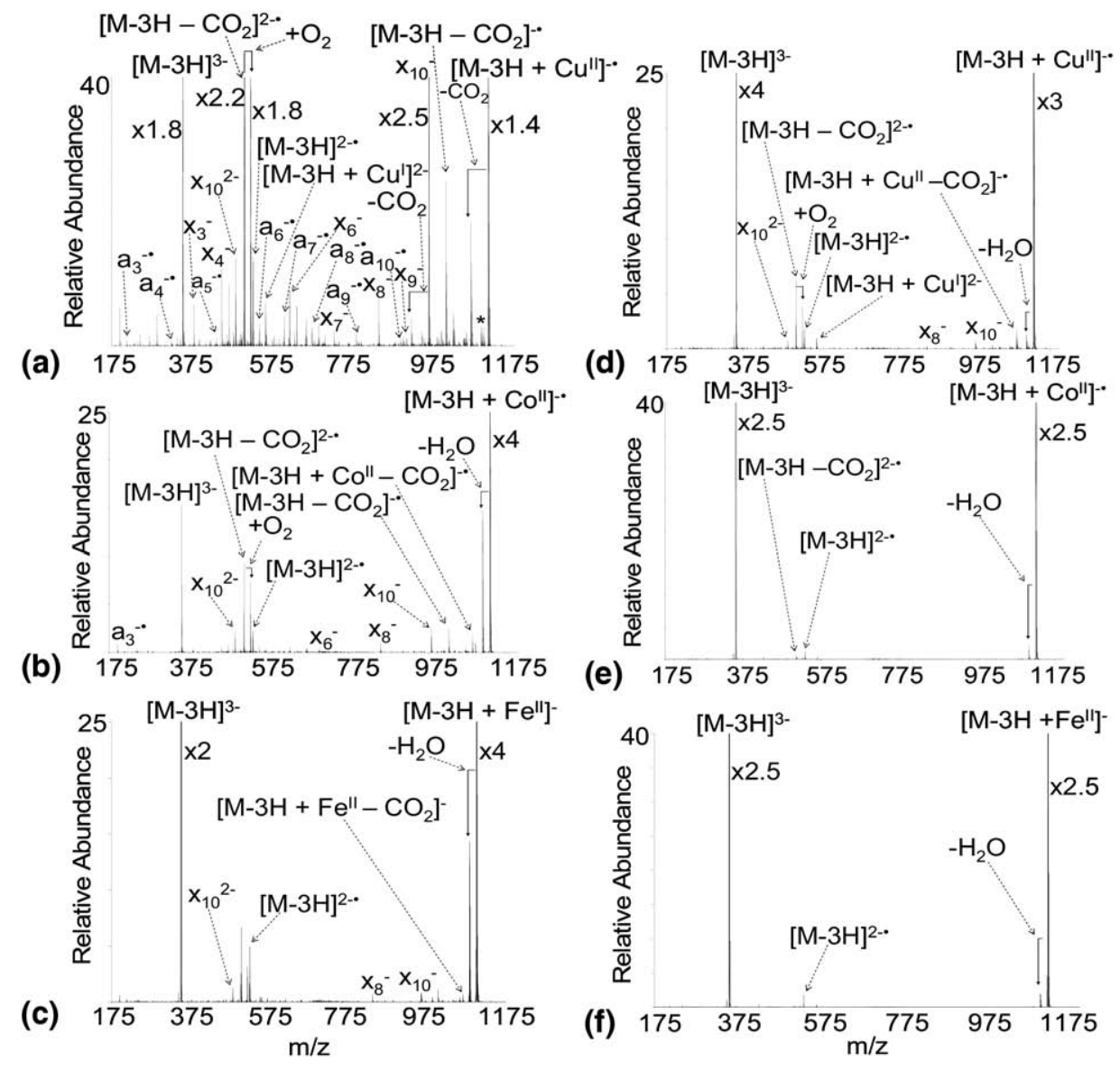

Figure 1. Ion/ion reaction between triply deprotonated DGAILDGAILD and (a) $\left[\mathrm{Cu}^{\mathrm{II}}(\mathrm{phen})_{2}\right]^{2+}$, (b) $\left[\mathrm{Co}^{\mathrm{II}}(\text { phen })_{2}\right]^{2+}$, (c) $\left[\mathrm{Fe}^{\mathrm{II}}(\text { phen })_{2}\right]^{2+}$, (d) $\left[\mathrm{Cu}^{\mathrm{II}}(\text { phen })_{3}\right]^{2+}$, (e) $\left[\mathrm{Co}^{\mathrm{II}}(\text { phen })_{3}\right]^{2+}$, and (f) $\left[\mathrm{Fe}^{\mathrm{II}}(\text { phen })_{3}\right]^{2+}$.

same tendencies were also noted for oligonucleotide anions [16]. For a given anion, the higher tendency for NETD with $\mathrm{Cu}(\text { phen })_{2}^{2+}$ can be attributed to its higher recombination energy as discussed elsewhere [16].

It is apparent from this comparison that the $\mathrm{Cu}(\text { phen })_{2}^{2+}$ complex is the most appropriate reagent of this set for electron-transfer, whereas the tris-phen complexes are most appropriate for divalent metal ion transfer. Figure 2 shows the results obtained for the [LPISASHpSpSKTR- $3 \mathrm{H}]^{3-} /\left[\mathrm{Cu}^{\mathrm{II}}(\text { phen })_{2}\right]^{2+} \bullet$ ion/ion reaction. This peptide anion was selected because it was subjected to electron-transfer to ionized xenon by Coon et al. [11] As with the model peptide DGAILDGAILD,

Table 1. Percentage of products from each of the two major pathways

\begin{tabular}{lcc}
\hline & $\begin{array}{c}\text { Electron } \\
\text { transfer }\end{array}$ & $\begin{array}{c}\text { Metal } \\
\text { insertion }\end{array}$ \\
\hline \hline [Cull(phen)2] $^{2+\bullet}+3$-DGAILDGAILD & $80 \pm 0.8$ & $20 \pm 0.8$ \\
[Coll(phen)2] $^{2+\bullet}+3$-DGAILDGAILD & $19 \pm 1$ & $81 \pm 1$ \\
[Fell(phen)2] $^{2+}+3$-DGAILDGAILD & $13 \pm 1$ & $87 \pm 1$ \\
[Cull(phen)3] $^{2+}+3$-DGAILDGAILD & $13 \pm 0.7$ & $87 \pm 0.7$ \\
[Coll(phen)3] $^{2+}+3$-DGAILDGAILD & $2 \pm 0.4$ & $98 \pm 0.4$ \\
[Fell(phen)3] $^{2+}+3$-DGAILDGAILD & $2 \pm 0.3$ & $98 \pm 0.3$ \\
\hline
\end{tabular}

product ions are observed from both major pathways with the electron-transfer path dominating. In addition to the a- and $\mathrm{x}$-type fragment ions that arise from NETD, there are abundant peaks that correspond to electron-transfer without dissociation (i.e., $[\mathrm{M}-3 \mathrm{H}]^{2-\bullet}$

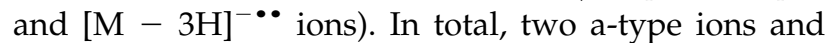
five $x$-type ions are observed and these reflect the cleavage of five of the peptide bonds. Many ions showed $\mathrm{CO}_{2}$ loss and most of the odd-electron products showed a degree of $\mathrm{O}_{2}$ attachment, as has been noted for radical z-type ions in this instrument [20]. No evidence for loss of either PTM was observed. Aside from the oxygen attachment and metal transfer products, all of the products observed with $\left[\mathrm{Cu}^{\mathrm{II}}(\text { phen })_{2}\right]^{2+} \cdot$ were also noted with $\mathrm{Xe}^{+\cdot}$. However, there were fewer primary backbone dissociation products, which translate to lower sequence coverage, and essentially no evidence for sequential dissociation reactions other than two-step processes associated with $\mathrm{CO}_{2}$ loss. These differences are likely to be largely due to the much higher recombination energy for the xenon cation (estimated to be $12.1 \mathrm{eV}$ based on the ionization energy) [21] relative to that of the transition-metal complex (estimated to be $8.4 \mathrm{eV}$ ) [20]. On this basis, $\left[\mathrm{Cu}^{\mathrm{II}}(\text { phen })_{2}\right]^{2+} \cdot$ 


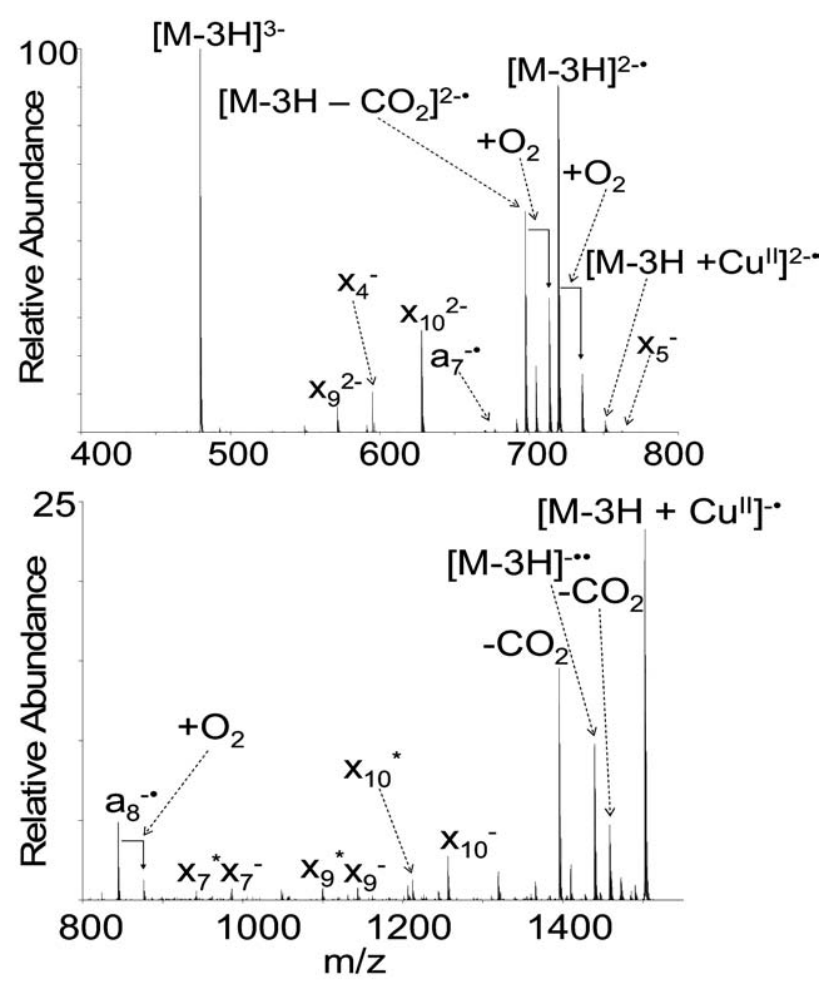

Figure 2. Post-ion/ion reactions product ion spectrum from the reaction between the triply deprotonated phosphopeptide LPISASHpSpSKTR and $\left[\mathrm{Cu}^{\mathrm{II}}(\text { phen })_{2}\right]^{2+} \cdot \mathrm{x}_{\mathrm{n}}{ }^{*}$ represents $\mathrm{CO}_{2}$ loss from the corresponding $\mathrm{x}$-ion.

is expected in general to be a softer reagent for NETD than ionized xenon. However, it is an electron-transfer reagent that is readily formed via electrospray and it has a relatively high mass-to-charge ratio $(\mathrm{m} / \mathrm{z}=211.5$ for the ${ }^{63} \mathrm{Cu}$ isotope), which is desirable for minimizing the $\mathrm{m} / \mathrm{z}$ range required for storing the oppositely charged ions.

The results presented here suggest that divalent transition metals can be transferred efficiently into multiplydeprotonated peptides via tris-phenanthroline complexes. The dissociation behavior of transition-metal containing peptides ions is very little explored. However, results that compare the CID of deprotonated DGAILDGAILD with CID of [DGAILDGAILD-3H $\left.+\mathrm{Co}^{\mathrm{II}}\right]^{-\bullet}$, available as supplementary material (Figure 1S), which can be found in the electronic version of this article, indicates that peptide anions with metal counter-ions can yield structural information that is complementary to that from the deprotonated species. In both cases, small molecule losses are prominent. The deprotonated species shows backbone cleavages $C$-terminal to aspartic acid residues (viz, Asp ${ }^{1}$ and Asp $^{6}$ ), whereas the metal complexed anion shows three backbone cleavages at the C-terminal end of the peptide. Further study of the dissociation of transition-metal containing peptide anions is needed, of course, before general observations can be made. However, it is apparent that it is straightforward to generate such anions from multiply charged peptide anions in the gas phase via ion/ion reactions.

\section{Conclusions}

The use of transition-metal complex cations as reagents for the gas-phase transformation of multiply deprotonated peptides into other ionic forms has been demonstrated. With a single reagent solution, it is possible to form both bis- and tris-phenanthroline complexes. The $\left[\mathrm{Cu}^{\mathrm{II}}(\text { phen })_{2}\right]^{2+} \cdot$ ion, due to its relatively high recombination energy, is well-suited for abstracting an electron from the peptide anion to give rise to a peptide radical anion, as well as to NETD. As such, it constitutes an NETD reagent that can be generated via spray ionization. The bis-phenanthroline complexes of the other two metals also gave rise to electron-transfer but metal transfer was much more extensive than with the $\left[\mathrm{Cu}^{\mathrm{II}}(\text { phen })_{2}\right]^{2+} \cdot$ ion. If the incorporation of a divalent transition-metal into a peptide anion is the objective, however, the tris-phen complexes are excellent reagents for the efficient generation of metal containing peptide anions in the gas-phase.

\section{Acknowledgments}

The authors acknowledge support for this work by the Office of Basic Energy Sciences, Division of Chemical Sciences, under award no. DE-FG02-00ER15105.

\section{Appendix A Supplementary Data}

Supplementary material associated with this article may be found in the online version at doi:10.1016/ j.jasms.2009.05.008.

\section{References}

1. Aebersold, R.; Goodlett, D. R. Mass Spectrometry in Proteomics. Chem. Rev. 2001, 101, 269-296.

2. Wells, J. M.; McLuckey, S. A. Collision-Induced Dissociation (CID) of Peptides and Proteins. Methods Enzymol. 2005, 402, 148-185.

3. Zubarev, R. A.; Kelleher, N. L.; McLafferty, F. W. Electron Capture Dissociation of Multiply Charged Protein Cations. A Nonergodic Process. J. Am. Chem. Soc. 1998, 120, 3265-3266.

4. Syka, J. E. P.; Coon, J. J.; Schroeder, M. J.; Shabanowitz, J.; Hunt, D. F. Peptide and Protein Sequence Analysis by Electron Transfer Dissociation Mass Spectrometry. Proc. Natl. Acad. Sci. U.S.A. 2004, 101, 95289533.

5. Bowie, J. H.; Brinkworth, C. S.; Dua, S. Collision-Induced Fragmentations of the $(\mathrm{M}-\mathrm{H})^{-}$Parent Anions of Underivatized Peptides: An Aid to Structure Determination and Some Unusual Negative Ion Cleavages. Mass Spectrom. Rev. 2002, 21, 87-107.

6. Bilusich, D.; Bowie, J. H. Fragmentations of $(\mathrm{M}-\mathrm{H})^{-}$Anions of Underivatized Peptides. Part 2: Characteristic Cleavages of Ser and Cys and of Disulfides and Other Post-Translational Modifications, Together with Some Unusual Internal Processes. Mass Spectrom. Rev. 2009, 28, 20-34.

7. Budnik, B. A.; Haselmann, K. F.; Zubarev, R. A. Electron Detachment Dissociation of Peptide Dianions: An Electron-Hole Recombination Phenomenon. Chem. Phys. Lett. 2001, 342, 299-302.

8. Wolff, J. J.; Laremore, A. M.; Busch, A. M.; Linhardt, R. J.; Amster, I. J. Electron Detachment Dissociation of Dermatan Sulfate Oligosaccharides. J. Am. Soc. Mass Spectrom. 2008, 19, 294-304.

9. Yang, J.; Mo, J.; Adamson, J. T.; Håkansson, K. Characterization of Oligodeoxynucleotides by Electron Detachment Dissociation Fourier Transform Ion Cyclotron Resonance Mass Spectrometry. Anal. Chem. 2005, 77, 1876-1882.

10. Herron, W. J.; Goeringer, D. E.; McLuckey, S. A. Gas-Phase Electron Transfer Reactions from Multiply Charged Anions to Rare Gas Cations. J. Am. Chem. Soc. 1995, 117, 11555-11562. 
11. Coon, J. J.; Shabanowitz, J.; Hunt, D. F.; Syka, J. E. P. Electron Transfer Dissociation of Peptide Anions. I. Am. Soc. Mass Spectrom. 2005, 16 , $880-882$.

12. Lam, C. N. W.; Chu, I. K. Formation of Anionic Peptide Radicals in Vacuo. J. Am. Soc. Mass Spectrom. 2006, 17, 1249-1257.

13. Hu, P. F.; Gross, M. L. Gas Phase Interactions of Transition Metal Ions and Dipeptides and Tripeptides: A Comparison with Alkaline Earth Metal Ion Interactions. J. Am. Chem. Soc. 1993, 115, 8821-8828.

14. Lee, S. W.; Kim, H. S.; Beauchamp, J. L. Salt Bridge Chemistry Applied to Gas-Phase Peptide Sequencing. Selective Fragmentation of Sodiated Gas-Phase Peptide Ions Adjacent to Aspartic Acid Residues. J. Am. Chem. Soc. 1998, 120, 3188-3195.

15. Pingitore, F.; Wesdemiotis, C. Characterization of Dipeptide Isomers by Tandem Mass Spectrometry of Their Mono- versus Di-Lithiated Complexes. Anal. Chem. 2005, 77, 1796-1806.

16. Barlow, C. K.; Hodges, B. D. M.; Xia, Y.; O’Hair, R. A. J.; McLuckey, S. A. Gas-Phase Ion/Ion Reactions of Transition Metal Complex Cations with
Multiply Charged Oligodeoxynucleotide Anions. J. Am. Soc. Mass Spectrom. 2008, 19, 281-293.

17. Van Berkel, G. J.; Asano, K. G.; Schnier, P. D. Electrochemical Processes in a Wire-in-a-Capillary Bulk-Loaded, Nano-Electrospray Emitter. J. Am. Soc. Mass Spectrom. 2001, 12, 853-862.

18. Xia, Y.; Liang, X.; McLuckey, S. A. Pulsed Dual Electrospray ionization for ion/ion reactions. J. Am. Soc. Mass Spectrom. 2005, 16, 1750-1756.

19. Xia, Y.; Chrisman, P. A.; Erickson, D. E.; Liu, J.; Liang, X. R.; Londry, F. A.; Yang, M. J.; McLuckey, S. A. Implementation of Ion/Ion Reactions in a Quadrupole/Time-of-Flight Tandem Mass Spectrometer. Anal. Chem. 2006, 78, 4146-4154.

20. Xia, Y.; Chrisman, P. A.; Pitteri, S. J.; Erickson, D. E.; McLuckey, S. A Ion/Molecule Reactions of Cation Radicals Formed from Protonated Polypeptides via Gas-Phase Ion/Ion Electron Transfer. J. Am. Chem. Soc. 2006, 128, 11792-11798

21. NIST Webbook, http://webbook.nist.gov. 